\title{
Knowledge of Mothers on Factors Associated with Anaemia among Children under Five Years Old in Orile-Agege General Hospital, Lagos, Nigeria
}

\author{
Josephine Oyebimpe Ajala and Abosede Catherine Ojerinde*
}

\author{
University College Hospital Ibadan, Ibadan, Nigeria
}

\begin{abstract}
Anaemia in children under five years old is a public health concern worldwide. In developing countries about 12 million children under five years old die each year from preventable causes. The deaths of over 6 million are either directly or indirectly attributed to malnutrition, mainly under-nutrition that leads to anaemia and constitutes a high percentage of infant and child mortality. This descriptive survey attempted to assess the knowledge of mothers on factors associated with anaemia among children under five years old in the child welfare clinic at Orile-Agege General Hospital, Lagos. The 120 respondents were conveniently selected and data was collected through a close ended question items and analyzed with Pearson Product Moment Correlation.

The findings revealed that $111(92.5 \%)$ of the respondents agreed that one of the major causes of anaemia was malnutrition. Consequently, respondents agreed that children who suffer from anaemia are prone to infections, delayed psychomotor development, poor academic performance and low scores in intelligent (IQ) tests which deprived them the opportunity to be physically fit and function at optimal level. There was no significant relationship between occurrence of anaemia and mothers' educational status $(r=.29)$ as well as their socio economic status $(r=.091)$. The religious belief of the respondents also had no bearing with the occurrence of anaemia $(r=.152)$. It was therefore recommended that there is need for more public enlightenment on the causes, prevention and complications of anaemia. Capacity building for health care providers to adequately equip them with updates and facts on the management of prevailing rate of anaemia effectively.
\end{abstract}

Keywords: Anaemia, culture, malnutrition, morbidity, mortality.

\section{INTRODUCTION}

Aim

To assess the knowledge of nursing mothers on factors associated with anaemia among children under five years old in Orile-Agege General Hospital. Lagos. Nigeria.

\section{Objectives}

- To assess socio economic factors associated to anaemia among children under five years old.

- To identify the effects of anaemia in children under five years old.

- To identify the relationship between mothers socio-economic factors and the occurrence of anaemia in children under five years

\section{Statement of the Problem}

The death of over 6 million children (55\%) are either directly or indirectly attributed, to malnutrition mainly under nutrition that lead to anaemia which constitutes greater percentage of infant and child mortality of which

*Address correspondence to this author at the Federal Training Center for Teachers of Health Sciences, University College Hospital Ibadan, Ibadan, Nigeria; Tel: +23 48033 423290; E-mail: chosenoje@yahoo.co.uk
Millennium Development Goal (MDG4) is set to reduce [1]. It is often associated with childhood malnutrition, producing interlinked factors, several of which could be causally related to mortality risk [2].

\section{Significance}

The result of the study will assist nurses and other health care providers in Orile-Agege General Hospital in correcting the misconceptions and other factors associated with anaemia in children under five years old attending the child welfare clinic of the study centre. The mothers will be more enlightened on the prevention of anaemia among children under five years old. Future researchers may also benefit from the findings.

\section{MATERIAL}

\section{Introduction}

According to WHO $[3,4]$ anaemia is said to be a global health problem in both developing and developed countries with major consequences on health as well as social and economic development which lead to disability. It is an unpleasant condition of the blood in which the quality and the quantity of the red blood cells haemoglobin is reduced, thus reducing its oxygen carrying capacity [4]. The prevalence of anaemia in developing countries is about four times 
more than developed countries [4] and it is the world's second leading cause of disability and thus one of the most serious global public health problems $[5,6]$. It affects over half of pre-school children in developing countries and at least $30-40 \%$ in industrialized countries. In poorer malaria endemic countries anaemia is one of the commonest preventable cause of death in children under five years old [7]. About two billion people are estimated to suffer from anaemia and it is reported to account for three quarters of 1 million deaths a year in Africa and South-East Asia [2].

\section{Reviewed Literature}

The common causes of anaemia among children under five years old in Nigeria include malaria, malnutrition, ignorance and beliefs due to religion and culture in the aspects of not eating nutritious food items [8]. Other causes are: pathological process or disease, decreased production of red blood cells, condition like deficiency of iron, vitamin B, folic acid zinc or other micro nutrient, infections, parasitic infestation and sickle cell anaemia [9]. In a quantitative and qualitative study conducted in Bushenyi Uganda on anaemia and associated factors among children under five years old and their mothers. The findings revealed that the overall prevalence of iron deficiency among children and their mothers was $26.2 \%$ and $17.9 \%$ respectively [10]. An investigation on the risk of anaemia in preschool age in West Africa detected that childhood anaemia was considered a severe public health problem in most countries of Sub-Sahara Africa [7].

In a related study conducted on factors associated with severe anaemia in Ebonyi State [10]. Children under five years old with severe anaemia $(P C V<15 \%$ and $\mathrm{HB}<5 \mathrm{~g} / \mathrm{dL}$ ) were included between January to June 2006, it revealed high mortality rate with severe anaemia, malnutrition, absence of blood transfusion and coma $[10,11]$.

\section{METHODS}

\section{Study Setting}

The study was conducted at Orile-Agege General Hospital, Lagos (a subsidiary of Lagos State University Teaching Hospital (LASUTH).) The hospital located within the metropolis of the capital city of Lagos State has one hundred and twenty bed spaces.

\section{Sampling \& Sample}

One hundred and twenty (120) mothers who were available and willing to participate in the study were conveniently selected.

\section{Reliability and Validity}

The test-retest reliability (Spearman rho correlation coefficient) showed a value of 0.570 (approximately $0.6)$ which indicated a moderate reliability. The face and content validity of the instrument was ensured by comparing it with previous similar studies, and was edited by two authors for critiques and necessary amendments.

\section{Ethical Consideration}

Data collection was approved by the Ethical Review Committee of the Lagos State Teaching Hospital. The participants were assured of confidentiality; therefore all data collected were coded. All information supplied by the respondents could not be linked in any way, and no identifying particulars of the participants were recorded on the result of the study

\section{Instrument}

All the question items were closed ended questions; Likert's scale was utilized to assess respondents' awareness, risk factors and effects of anaemia among children under five years old.

\section{Data Collection}

Two research assistants worked with the researcher in the data collection and only the mothers willing and available responded. The questionnaires were distributed to the mothers as they arrive at the clinic. A translated Yoruba language version of the questionnaire was utilized for the non-educated among them for effective communication and understanding of the question items. Data collection spanned 2 weeks.

\section{Data Analysis}

These were analysed using simple percentage distribution and frequency and the result was presented in tables. The objectives of the study were analyzed by running frequency and percentage on the variables. The hypotheses were analysed using Pearson's Product-Moment Correlation and the significant level was fixed at 0.05

\section{Hypotheses}

1. There is no significant relationship between the occurrence of anaemia and mothers' socio economic status.

2. There is no significant relationship between the occurrence of anaemia and mothers' education. 
3. There is no significant relationship between the occurrence of anemia and religious belief of the respondents.

\section{Conceptual Framework}

The constructs of The Health Belief Model [12] are Perceived susceptibility (an individual's assessment of their risk of getting the condition), perceived severity (an individual's assessment of the seriousness of the condition and its potential consequences). Perceive barriers (an individual's assessment of the influences that facilitate or discourage adoption of the promoted behaviour) and perceived benefits (an individual's assessment of the positive consequences of adopting the behaviour). Cues to action (these are events or things that move people to change their behaviour) and finally Self-efficacy is the confidence in one's ability to take action.

The Health Belief Model was conceptualized to the studied variables of the factors associated with anaemia among children under five years. Nursing mothers' knowledge and awareness of the causes of anaemia and the potential consequences of not providing adequate balanced diet for the child were the perceived susceptibility and severity (e.g. malnutrition, infection, economic consequences such the costs incurred by the public and private sectors in therapeutic measures for the prevalent level of anaemia etc Perceived barriers were the predisposing factors (socio- cultural factors, illiteracy, religion etc) of anaemia among children under five years old. Perceived benefits are healthy child, immune response, etc. while the cues of action includes health education on socio-cultural factors that can predispose to anaemia, counseling, women empowerment, etc and self efficacy is the opportunity for mothers to receive health education on the importance of adequate balance diet.

\section{RESULT}

The socio-demographic variables (Table 1) showed that $49.2 \%$ of the respondents were within the age range of $31-35$ years, majority $(45.8 \%)$ were school certificate holders while $46.7 \%$ were self employed, $60 \%$ were of Yoruba tribe and $80 \%$ were Christians. In Table 2, about a quarter (35\%) of the mothers disagreed with the statement that children from the home where both parents have formal education always develop anemia, while majority (92.5\%) stated that eating proteinous diet (Fish, egg, meat etc.) can prevent anaemia among under five children.78\% disagreed that serving food that contains meat, fish and egg is likely to encourage children to steal later in life and $59.2 \%$ agreed that a family must be wealthy to prevent the occurrence of anemia.

Table 1: Mothers' Socio-Demographic Data

\begin{tabular}{|c|c|c|c|}
\hline $\mathbf{S} / \mathbf{n}$ & Variables & $N=120$ & $\%$ \\
\hline \multirow[t]{5}{*}{ A. } & \multicolumn{3}{|l|}{ Age } \\
\hline & $18-25$ & 22 & 18.3 \\
\hline & $26-30$ & 27 & 22.5 \\
\hline & $31-35$ & 59 & 49.2 \\
\hline & 36 above & 12 & 10 \\
\hline \multirow[t]{4}{*}{ B. } & \multicolumn{3}{|l|}{ Marital Status } \\
\hline & Married & 111 & 92.5 \\
\hline & Single & 09 & 7.5 \\
\hline & Widow & Nil & - \\
\hline \multirow[t]{4}{*}{ C. } & \multicolumn{3}{|l|}{ Highest Education } \\
\hline & Primary & 47 & 39.2 \\
\hline & School certificate & 55 & 45.8 \\
\hline & Tertiary & 18 & 15 \\
\hline \multirow[t]{5}{*}{ D. } & \multicolumn{3}{|l|}{ Occupation } \\
\hline & Housewife & 31 & 25.8 \\
\hline & Civil servant & 01 & 0.8 \\
\hline & Trading & 32 & 26.7 \\
\hline & Self employed & 56 & 46.7 \\
\hline \multirow[t]{6}{*}{ E. } & \multicolumn{3}{|l|}{ Tribe } \\
\hline & Yoruba & 72 & 60 \\
\hline & Igbo & 29 & 24.2 \\
\hline & Igbira & 15 & 12.5 \\
\hline & Others & 4 & 3.3 \\
\hline & Hausa & $\mathrm{Nil}$ & - \\
\hline \multirow[t]{3}{*}{ F. } & \multicolumn{3}{|l|}{ Religion } \\
\hline & Christianity & 96 & 80 \\
\hline & Islam & 24 & 20 \\
\hline
\end{tabular}

The result also identified poor academic performance, infections, lower scores on inteligent (IQ) tests, and delayed psychomotor development as the effects of anaemia (Table 3) $90 \%$ of the respondents generally agreed that children with anemia are prone to infections while $10 \%$ disagreed with the statement. Table 3 showed that $75 \%$ of the respondents agreed that children with low haemoglobin level are academically poor while the remaining $25 \%$ disagreed with the statement. 
Table 2: Mothers' Response on Factors Associated with Anaemia

\begin{tabular}{|c|c|c|c|}
\hline \multirow{2}{*}{$\mathbf{S} / \mathbf{n}$} & \multirow{2}{*}{ Variables } & \multicolumn{2}{|c|}{ Response $\mathrm{N}=120$} \\
\hline & & Yes (\%) & No (\%) \\
\hline 1 & Children from the home where both parents have formal education always develop anemia & $\begin{array}{c}42 \\
(35)\end{array}$ & $\begin{array}{c}78 \\
(65)\end{array}$ \\
\hline 2 & Eating of proteinous diet can prevent anaemia among under five children (Fish, egg, meat etc.) & $\begin{array}{c}111 \\
(92.5)\end{array}$ & $\begin{array}{c}9 \\
(7.5)\end{array}$ \\
\hline 3 & Serving food that contain meat, fish and egg is likely to encourage children to steal later in life. & $\begin{array}{c}29 \\
(24.2)\end{array}$ & $\begin{array}{c}91 \\
(75.8)\end{array}$ \\
\hline 4 & A family must be wealthy to prevent the occurrence of anaemia & $\begin{array}{c}71 \\
(59.2)\end{array}$ & $\begin{array}{c}49 \\
(40.8)\end{array}$ \\
\hline
\end{tabular}

Table 3: Mothers' Response on Effects of Anaemia

\begin{tabular}{|c|c|c|c|}
\hline \multirow{2}{*}{$\mathbf{S} / \mathbf{n}$} & \multirow{2}{*}{ Variables } & \multicolumn{2}{|c|}{ Response $\mathrm{N}=120$} \\
\hline & & Yes (\%) & No $(\%)$ \\
\hline 1 & Infections & $\begin{array}{l}108 \\
(90)\end{array}$ & $\begin{array}{c}12 \\
(10)\end{array}$ \\
\hline 2 & Poor academic performance & $\begin{array}{c}90 \\
(75)\end{array}$ & $\begin{array}{c}30 \\
(25)\end{array}$ \\
\hline 3 & Delayed psychomotor development & $\begin{array}{l}105 \\
87.5\end{array}$ & $\begin{array}{c}15 \\
12.5\end{array}$ \\
\hline 4 & Lower scores on intelligence (IQ) tests & $\begin{array}{c}93 \\
77.5\end{array}$ & $\begin{array}{c}27 \\
22.5\end{array}$ \\
\hline
\end{tabular}

\section{DISCUSSION OF THE FINDINGS}

This study was aimed at assessing the knowledge of nursing mothers on some of the factors associated with anaemia among children under five years old. The underlying causes of anaemia are many, varied and largely preventable; these include nutritional deficiencies, infections and heamoglobin disorders. The study revealed that (Table 2) parents who had formal education are likely to be well informed about the importance of balanced diet as well as the consequences of not feeding their children with adequate balanced diet. As a result, their children may not likely develop anemia. Serving food that contains meat, fish and egg may not necessarily encourage children to steal in the nearest future as this statement may be a mere superstition without any empirical support. The few who agreed with the statement may likely to be those who belong to the school of thought that a child should neither eat meat nor fish. This was in line with the finding from a study which ascertained that nutritional deficiency among other factors was associated with anaemia in children under five years old [13]. This also corroborated with a similar study which described under-nutrition as a culturally based cause of anaemia [5]. The effect (Table 3) of iron deficiency on the immune system occurs due to a lowered concentration of cells responsible for cellmediated immunity leading to infection as a consequence. There is every tendency for the children to be irregular in school as a result of poor state of health. Consequently, their academic performance may be adversely affected [10]. The relationship between anemia and infection remains controversial. Anaemia is an immunosuppressive factor, as mild iron deficiency protects against infection, because hypoferremia reduces the amount of iron available for use by pathogens. In contrast, humoral immunity is not affected by iron deficiency, and the significance of hypoferremia in the growth of microorganisms is doubtful. However, it is generally accepted that excess or deficiency of iron result in changes in immune response [3]. This is in line with the findings of a study conducted at Ekiti State University Teaching Hospital that anaemia was a major cause of paediatrics hospital admission and death in many African countries [1]. It also agreed with a study conducted in Arizona on the prevention of iron deficiency in infants and toddlers with the use of Bayley Scales of Infant Development. Infants with iron deficiency anemia received lower scores on mental and motor tests, including gross and fine motor coordination, and demonstrated affective differences, such as wariness, fearfulness, and unhappiness [14]. 
There is no significant relationship between the occurrence of anaemia and mothers' education $(r=0.29)$ and socio-economic status $(r=0.091)$. The occurrence of anaemia is not significantly related to socio-economic status of the respondents. This implies that whatever may be the socio- economic status (either upper or lower) it does not indicate the occurrence of anaemia i.e. anybody is prone to anaemia regardless of the socio-economic status. The implication of the low positive correlation between the educational background of the mother and the occurrence of anaemia is that mothers' educational status may not necessarily influence the incidence of anaemia. It very possible for one to have a sound educational background or attained a high level of education but have little knowledge or exhibit a negative attitude towards health issues. This is contrary to a study in Pakistan which revealed that with higher education of mother and family income, symptoms of anaemia decreased and level of haemoglobin increased both for the mother and child [15].

There is no significant relationship between the occurrence of anaemia and religious belief of the respondents. This assumes that regardless of the religious practices of the respondents either Christianity, Islam or otherwise has no significant relationship with the occurrence of anaemia. This indicates that anybody can be a victim regardless of the religion in as much as the adequate care and prevention are not put in place. This finding was against the belief that people have in the past when anaemia was associated with evil powers, witchcraft and the likes.

\section{CONCLUSION}

The study revealed that there is awareness if not much about the causes prevention and dangers associated with anaemia as against the old belief that anaemia was associated with evil power and witchcraft, but still, more need to done to reduce the cases of anaemia to the barest minimum. It is necessary for all stakeholders in health care sector to put in more efforts by enlightening the general populace and make adequate provision for care and treatment of anaemia. Capacity building for nurses should be of paramount important. This will help them to keep abreast with recent findings and update their knowledge about how to effectively manage cases of anaemia. All these will go a long way in reducing the incidence of anaemia.

\section{REFERENCES}

[1] Adesokan FOO Reproductive health for all ages 2nd ed. Faxwell Nigeria limite Ekiti State Nigeria 2011.

[2] Adegoke S, Ayansanwo A, Isaac O, Okeniyi J. Iron deficiency in childhood. Peadiatrics Med J 2010; 8: 12-5.

[3] Ferreira dos Santos R, Campos Gonazalez ES, Grade de Arrud IC. Prevalence of anaemia in under five year old children in a children's hospital in Recife, Brazil. J Rev Brasil Hematol Hermoter 2011; 33: [cited 2014 April1]; Available from www.ncbi.nlm.nih.gov/pmc

[4] World Health Organization Iron deficiency anaemia: assessment, prevention and control: a guide for program managers; Geneva; W H O 2001.

[5] Onyemaobi GA, Onimawo IA. Anaemia prevalence among under-five in Imo state Nigeria. Aust J Basic Appl Sci 2011; 5: 122-7. [cited 2014 March 15]; Available from http://connection.ebscohost.com

[6] World Health Organization protecting, promoting and supporting breastfeeding: a joint WHO/UNICEF statement 1989 Geneva.

[7] World Health Organization. Worldwide prevalence of anaemia (2005-2011) WHO global data base on anaemia 2011 [cited 2014 March 10]; Available from http/who/intpublications

[8] Ewusie JE, Ahiadeke C, Beyene J, Hamid JS. Anaemia among under-5 children in the Ghanaian population: estimates from the Ghana demographic and health survey. J BMC Public Health 2014; 14: 626. [cited 2014 June 20]; Available from http://www.biomedcentral.com/1471. 2458/14/626

[9] Fleming AF, Menendez G, Alonso PL. Malaria related anaemia. Parasitol J Today 2000; 16: 469-76. http://dx.doi.org/10.1016/S0169-4758(00)01774-9

[10] Muoneke VV, Roland C, Ibekwe HV, et al. Factors associated with mortality in under-five children with severe anemia in Ebonyi, Nigeria. Indian Pediatric 2012; 49: 119-23. [cited 2014 January 3]; Available from http://www.indianpediatrics.net/feb2012/feb-

[11] Sabitu K, lliyasu Z, Hassan SS, Mande AT. Evaluation of a community level nutritional information system for action in a rural community of Zaria, northern Nigeria. Ann African Med 2004; 3: 120-5.

[12] Janz NK, Marshall HB. The health belief model: a decade later. J Health Educ Behavior 1989; 11: 1-47. [cited2014 June 20]; Available from http://sphweb.bumc.bu.edu/otlt/ MPH-Modules/SB/SB721-Models/SB721-Models2.html

[13] Brugnara C, Platt OS. The neonatal erythrocyte and its disorders in hematology of infant and childhood 7th ed. Nathan DC Orkin Philadelphia. 2009.

[14] Kazal LA. Prevention of iron deficiency in infants and toddler. Am Fam Physician 2002; 1; 66: 1217-22. [cited 2014 June 20]; Available from www.aafp.org/afp

[15] Zahira B, Muhammad IZ, Ashfaq AM, Tanvir A. Socio-cultural factors affecting anemia and their effects on mother, and child health in rural areas of district Faisalabad, Punjab, Pakistan. Pak J Agri Sci 2010; 47: 59-65. [cited 2014 February 21]; Available from http://www.pakjas.com.pk 